\title{
Berberine alleviates palmitic acid-induced podocyte apoptosis by reducing reactive oxygen species-mediated endoplasmic reticulum stress
}

\author{
XING-YANG XIANG ${ }^{1 *}$, TING LIU $^{2 *}$, YUE WU ${ }^{3}$, XU-SHUN JIANG ${ }^{1}$, \\ JUN-LING HE ${ }^{4}$, XUE-MEI CHEN ${ }^{5}$ and XIAO-GANG DU ${ }^{1,6}$
}

\author{
${ }^{1}$ Department of Nephrology, The First Affiliated Hospital of Chongqing Medical University, Chongqing 400042; \\ ${ }^{2}$ Department of Nephrology, Chengdu Fifth People's Hospital, Chengdu, Sichuan 611130; ${ }^{3}$ Department of Obstetrics and \\ Gynecology, The First Affiliated Hospital of Chongqing Medical University, Chongqing 400042, P.R. China; \\ ${ }^{4}$ Department of Pathology, Leiden University Medical Center, 2333 ZA Leiden, The Netherlands; ${ }^{5}$ Emergency Department, \\ The First Affiliated Hospital of Chongqing Medical University; ${ }^{6}$ The Chongqing Key Laboratory of \\ Translational Medicine in Major Metabolic Diseases, The First Affiliated Hospital \\ of Chongqing Medical University, Chongqing 400042, P.R. China
}

Received December 16, 2019; Accepted June 22, 2020

DOI: $10.3892 / \mathrm{mmr} .2020 .11641$

\begin{abstract}
Lipid accumulation in podocytes can lead to the destruction of cellular morphology, in addition to cell dysfunction and apoptosis, which is a key factor in the progression of chronic kidney disease (CKD). Berberine (BBR) is an isoquinoline alkaloid extracted from medicinal plants such as Coptis chinensis, which has been reported to have a lipid-lowering effect and prevent CKD progression. Therefore, the present study aimed to investigate the effect of BBR on palmitic acid (PA)-induced podocyte apoptosis and its specific mechanism using an in vitro model. Cell death was measured using the Cell Counting Kit- 8 colorimetric assay. Cell apoptotic rate was assessed by flow cytometry. The expression of endoplasmic reticulum (ER) stress- and apoptosis-related proteins was detected by western blotting or immunofluorescence. Reactive oxygen species (ROS) were evaluated by 2',7'-dichlorofluorescein diacetate fluorescence staining. The results
\end{abstract}

Correspondence to: Dr Xiao-Gang Du, Department of Nephrology, The First Affiliated Hospital of Chongqing Medical University, 1 Youyi Road, Chongqing 400042, P.R. China

E-mail: cqmudxg@163.com

"Contributed equally

Abbreviations: BIP, binding immunoglobulin protein; PERK, protein kinase RNA-like endoplasmic reticulum kinase; ATF4, activating transcription factor 4 ; $\mathrm{CHOP}, \mathrm{C} / \mathrm{EBP}$ homologous protein; ATF6, activating transcription factor 6; IRE1 $\alpha$, inositol-requiring enzyme $1 \alpha$

Key words: berberine, podocyte, apoptosis, palmitic acid, endoplasmic reticulum stress, reactive oxygen species of the present study revealed that BBR treatment decreased PA-induced podocyte apoptosis. In addition, 4-phenylbutyric acid significantly reduced PA-induced cell apoptosis and the expression of ER stress-related proteins, which indicated that ER stress was involved in PA-induced podocyte apoptosis. In addition, $\mathrm{N}$-acetylcysteine inhibited $\mathrm{PA}$-induced excessive ROS production, ER stress and cell apoptosis of podocytes. BBR also significantly reduced PA-induced ROS production and ER stress in podocytes. These results suggested that PA mediated podocyte apoptosis through enhancing ER stress and the production of ROS. In conclusion, BBR may protect against PA-induced podocyte apoptosis, and suppression of ROS-dependent ER stress may be the key mechanism underlying the protective effects of BBR.

\section{Introduction}

Chronic kidney disease (CKD), including diabetic nephropathy $(\mathrm{DN})$, is frequently accompanied by dyslipidemia, which in turn promotes the occurrence and progression of CKD (1-4). Dyslipidemia is mainly manifested as decreased high density lipoprotein-C levels, and high levels of serum triglycerides and long-chain free fatty acids (FFAs) (1). Lipid accumulation, including the presence of saturated FFAs in the glomeruli and proximal tubules, may induce endoplasmic reticulum (ER) stress and generation of reactive oxygen species (ROS), ultimately leading to cellular lipotoxicity, apoptosis and inflammation, which serve an important role in advanced CKD (5).

As terminal differentiated cells, podocyte injury has been considered a vital event in the pathological mechanism of CKD. Changes in podocyte structure and podocytopenia can cause proteinuria and renal dysfunction, and can eventually contribute to the development of DN $(6,7)$. During the onset and development of DN, lipid accumulation in podocytes 
enhanced by high glucose has been reported to have a key role in podocyte injury (8). Oxidative stress, ER stress and the development of inflammation may be the main mechanisms underlying podocyte damage caused by excess lipids $(9,10)$. Furthermore, palmitic acid (PA), which is a type of saturated FFA, is abundant in human plasma, and increased levels of FFAs have been demonstrated to be detrimental to various cell types, including podocytes (11). Previous studies have revealed that PA-induced podocyte apoptosis may be ameliorated by reducing ER stress $(10,12)$. In our previous study, oxidative stress was demonstrated to be involved in fatty acid-induced podocyte apoptosis (13).

Berberine (BBR) is a Chinese medicine originally extracted from Coptis root and Phellodendron, which has been widely used as a clinical medicine to treat diarrhea in China $(14,15)$. Previous studies reported the therapeutic effects of BBR on hypertension and hyperlipidemia, with no severe side effects $(16,17)$. BBR has been used in DN treatment because it inhibits oxidative stress and aldose reductase (18). In addition, it has been shown that BBR may clearly attenuate the progression of nonalcoholic fatty liver disease by targeting ER stress in vivo and in vitro (19). Our previous study also revealed that BBR may ameliorate Aldo-induced podocyte injury by inhibiting oxidative stress and ER stress (20). However, it is not clear whether BBR has a similar effect on PA-induced podocyte apoptosis. Therefore, the specific mechanism underlying the protective effects of BBR on PA-induced podocyte apoptosis was explored in the present study.

\section{Materials and methods}

Cell culture and treatment. The conditionally immortalized mouse podocyte cell line MPC5 was kindly donated by Dr Ruan (Centre for Nephrology, Royal Free and University College Medical School, London, UK) and was cultured as previously described (21). Briefly, the cells were cultured in RPMI-1640 (Gibco; Thermo Fisher Scientific, Inc.) containing $10 \%$ fetal bovine serum (Gibco; Thermo Fisher Scientific, Inc.), penicillin $(100 \mathrm{U} / \mathrm{ml})$, streptomycin $(100 \mu \mathrm{g} / \mathrm{ml})$ and $10 \mathrm{U} / \mathrm{ml}$ interferon- $\gamma$ (IFN- $\gamma$; PeproTech, Inc.) at $33^{\circ} \mathrm{C}$ in an atmosphere containing $5 \% \mathrm{CO}_{2}$. Once cell confluence reached $70-80 \%$, cells were cultured in RPMI-1640 complete medium without $10 \mathrm{U} / \mathrm{ml} \mathrm{IFN}-\gamma$ at $37^{\circ} \mathrm{C}$ in an atmosphere containing $5 \% \mathrm{CO}_{2}$ for $10-14$ days to induce podocyte differentiation. The differentiated podocytes which were polygonal with foot-like structures were subsequently treated with PA $(150 \mu \mathrm{mol} / \mathrm{l})$ for $24 \mathrm{~h}$, following pretreatment with BBR $(8 \mu \mathrm{mol} / \mathrm{l})$, 4-phenylbutyric acid (4-PBA; $10 \mu \mathrm{mol} / \mathrm{l}$ ) or $\mathrm{N}$-acetylcysteine (NAC; $150 \mu \mathrm{mol} / 1$; all from Sigma-Aldrich; Merck KGaA) for $2 \mathrm{~h}$ at room temperature.

Western blot analysis. After treatment with the aforementioned reagents, floating cells were collected in an Eppendorf tube, centrifuged at $800 \mathrm{x} \mathrm{g}$ for $3 \mathrm{~min}$ at room temperature and the supernatant was removed. Cells in the Eppendorf tube and cultured cells remaining in the petri dish were washed twice with 1X PBS and lysed in RIPA lysis buffer (Beyotime Institute of Biotechnology) containing protease inhibitors on ice. Subsequently, the cells were sonicated $(20-25 \mathrm{KHz}$ at $4^{\circ} \mathrm{C}$ ) for $15 \mathrm{sec}$ and centrifuged at $12,000 \mathrm{x}$ g for $12 \mathrm{~min}$ at $4^{\circ} \mathrm{C}$ to obtain the total protein samples. Protein samples were then heated at $100^{\circ} \mathrm{C}$ for $10 \mathrm{~min}$ after determination of protein concentration using a bicinchoninic acid protein assay kit (Beyotime Institute of Biotechnology), and were mixed with loading buffer. Subsequently, proteins $(1-3 \mathrm{mg} / \mathrm{ml})$ were separated by SDS-PAGE on $10 \%$ gels, transferred onto PVDF membranes (EMD Millipore) and blocked with 5\% non-fat milk for $3 \mathrm{~h}$ at room temperature. The PVDF membranes were then incubated overnight at $4^{\circ} \mathrm{C}$ with antibodies against $\beta$-actin (1:5,000; cat. no. KM9001T; Tiangin Sungene Biotech Co., Ltd.), binding immunoglobulin protein (BIP; 1:1,000; cat. no. 3177; Cell Signaling Technology, Inc.), protein kinase RNA-like ER kinase (PERK; 1:1,000; cat. no. WL03378; Wanleibio Co., Ltd.), activating transcription factor (ATF) 4 (1:1,000; cat. no. 11815; Cell Signaling Technology, Inc.), C/EBP homologous protein (CHOP; 1:1,000; cat. no. 5554; Cell Signaling Technology, Inc.), ATF6 (1:1,000; cat. no. 65880; Cell Signaling Technology, Inc.), inositol-requiring enzyme $1 \alpha$ (IRE1 $\alpha$; 1:1,000; cat. no. 3294; Cell Signaling Technology, Inc.), caspase 12 (1:1,000; cat. no. 2202; Cell Signaling Technology, Inc.), and cleaved-caspase 3 (1:1,000; cat. no. 9664; Cell Signaling Technology, Inc.). Subsequently, the membranes were washed and incubated with horseradish peroxidase-conjugated secondary antibodies [mouse; 1:5,000; cat. no. GAM007; and rabbit; 1:5,000; cat. no. GAR007; Multisciences (Lianke) Biotech Co., Ltd.] for $1 \mathrm{~h}$ at room temperature. Blots were then incubated with a chemiluminescence staining reagent kit (Advansta, Inc.), and the proteins were detected using a chemiluminescence system (Fusion FX5; Vilber Lourmat). Protein intensity was semi-quantified with Fusion analysis software (FX5; Vilber Lourmat).

Immunofluorescence.Podocytes grownoncoverslips to 70-80\% confluence were washed with $1 \mathrm{X}$ PBS, fixed in $4 \%$ paraformaldehyde for $30 \mathrm{~min}$, permeabilized with $0.2 \%$ Triton X-100 for $10 \mathrm{~min}$ and blocked with 5\% BSA (Sigma-Aldrich; Merck $\mathrm{KGaA}$ ) for $1 \mathrm{~h}$, all at room temperature. The cells were then incubated with rabbit anti-BIP antibody (1:200; Cell Signaling Technology, Inc.) at $4^{\circ} \mathrm{C}$ overnight, followed by incubation with a green-fluorescence Alexa Fluor ${ }^{\circledR} 488$ goat anti-rabbit IgG antibody (1:400; cat. no. A11008, Invitrogen; Thermo Fisher Scientific, Inc.) for $1 \mathrm{~h}$ at $37^{\circ} \mathrm{C}$, and counterstaining with DAPI for $5 \mathrm{~min}$ at room temperature. Finally, images were observed under a fluorescence microscope.

Measurement of ROS. Podocytes were cultured in 12-well plates to $70-80 \%$ confluence, washed with $1 \mathrm{X}$ PBS after treatment with the aforementioned reagents and incubated with $10 \mu \mathrm{mol} / 1$ 2',7'-dichlorofluorescein diacetate (DCFH-DA; Sigma-Aldrich; Merck KGaA) for $30 \mathrm{~min}$ at $37^{\circ} \mathrm{C}$. Cell fluorescence was detected using a fluorescence microscope, with an excitation wavelength of $488 \mathrm{~nm}$ and an emission wavelength of $525 \mathrm{~nm}$.

Flow cytometric analysis. An Annexin V-FITC/propidium iodide (PI) apoptosis assay kit (Tiangin Sungene Biotech Co., Ltd.) was applied to detect cell apoptosis, according to the manufacturer's protocol. Briefly, cells at 70-80\% confluence were harvested and washed with cold $1 \mathrm{X}$ PBS twice. Subsequently, the cells were centrifuged at $1,000 \mathrm{xg}$ at $4^{\circ} \mathrm{C}$ for 
A

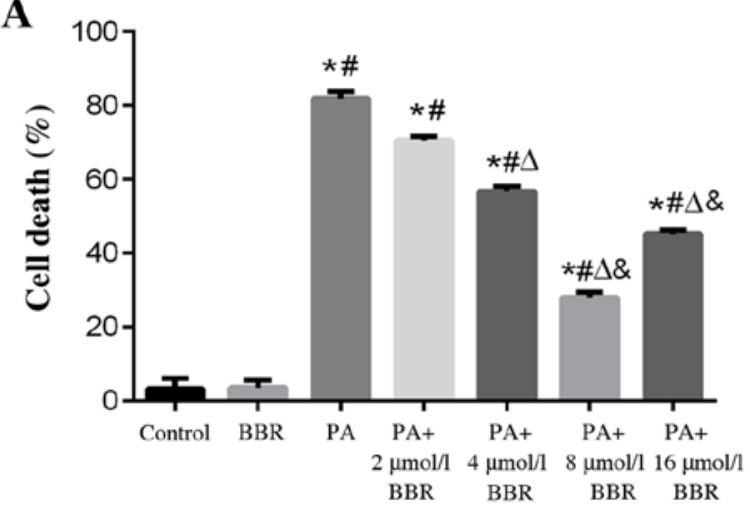

C
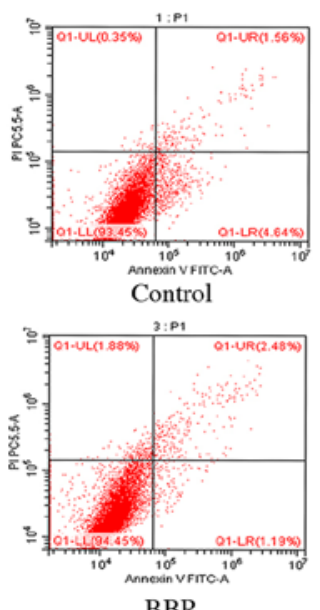

BBR
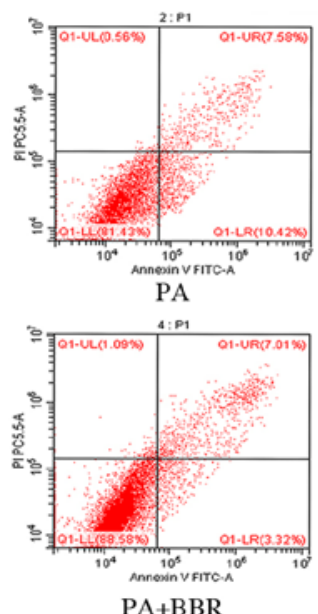

B

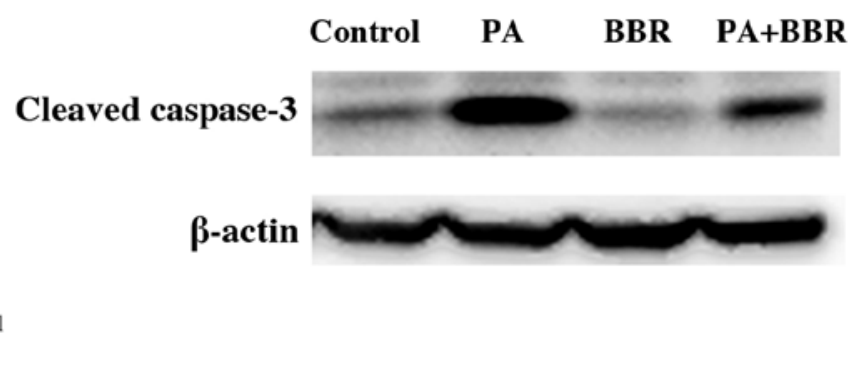

E

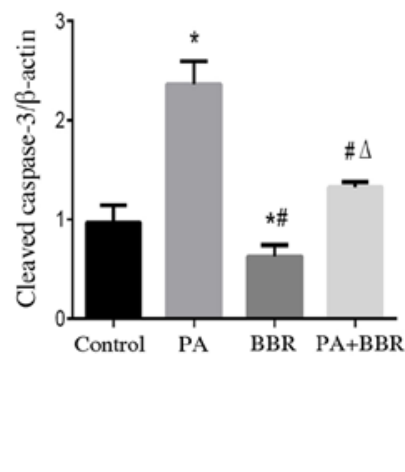

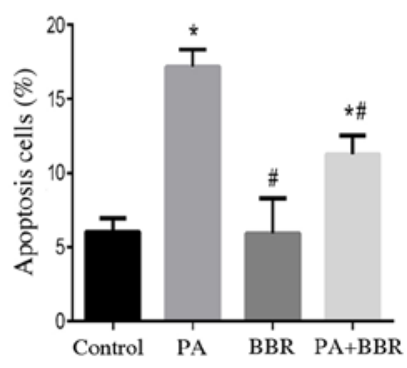

Figure 1. BBR alleviates PA-induced podocyte death and apoptosis. (A) Cell death was evaluated by Cell Counting Kit- 8 assay after the podocytes were treated with PA $(150 \mu \mathrm{mol} / 1)$ for $24 \mathrm{~h}$ after pretreatment with different concentrations of $\mathrm{BBR}$ for $2 \mathrm{~h} .{ }^{*} \mathrm{P}<0.05$ vs. control group, ${ }^{\sharp} \mathrm{P}<0.05$ vs. BBR group, ${ }^{\Delta} \mathrm{P}<0.05 \mathrm{vs}$. $\mathrm{PA}$ group, ${ }^{\&} \mathrm{P}<0.05 \mathrm{vs} . \mathrm{PA}+2 \mu \mathrm{mol} / 1 \mathrm{BBR}$ group. (B) Representative expression of cleaved-caspase 3 , as detected by western blot analysis after treatment with PA $(150 \mu \mathrm{mol} / \mathrm{l})$ and/or BBR $(8 \mu \mathrm{mol} / 1)$. (C) Representative plots of apoptosis analyzed by flow cytometry. (D) Densitometric analysis of the results shown in (B). (E) Quantification of podocyte apoptosis. Data are presented as the mean \pm standard error of the mean $(n=3)$. ${ }^{*} \mathrm{P}<0.05$ vs. control group, ${ }^{\sharp} \mathrm{P}<0.05$ vs. PA group, ${ }^{\Delta} \mathrm{P}<0.05$ vs. BBR group. BBR, berberine; PA, palmitic acid; PI, propidium iodide.

5 min, resuspended in $300 \mu$ l binding buffer, and then incubated with $5 \mu$ l Annexin V-FITC and $5 \mu$ PI for 15 min at room temperature in the dark. Subsequently, $200 \mu$ l binding buffer was added to each sample tube and the cells were analyzed using a BD FACSVantage SE cytometer (BD Biosciences). Annexin V-positive/PI-negative podocytes were considered to indicate the early stages of apoptosis, whereas Annexin $\mathrm{V}$-positive/PI-positive podocytes were considered to indicate late apoptotic or necrotic cells. The apoptotic rate of podocytes was calculated as the sum of early and late apoptosis cells.

Cell counting Kit-8 (CCK-8). CCK-8 (Dojindo Molecular Technologies, Inc.) was used to determine cell death and viability, according to the manufacturer's instructions. Briefly, the cells were cultured in 96 -well plates $\left(3.0 \times 10^{3}\right.$ cells/well). Podocytes were treated with PA $(150 \mu \mathrm{mol} / \mathrm{l})$ for $24 \mathrm{~h}$ after pretreatment with different concentrations of BBR $(2,4,8$ and $16 \mu \mathrm{mol} / \mathrm{l}$ ) for $2 \mathrm{~h}$, and then incubated at $37^{\circ} \mathrm{C}$ for $2 \mathrm{~h}$ after the addition of $10 \mu \mathrm{l} \mathrm{CCK-8}$ working reagent and $90 \mu \mathrm{l}$ RMPI-1640 medium to each well. The absorbance was measured at $450 \mathrm{~mm}$ with a spectrophotometer (Thermo Fisher Scientific, Inc.). The cell death rate was calculated by formula: [1-A450 (experimental)/A450 (control)] x100.
Statistical analysis. Statistical analyses were performed with Graph Pad Prism 6.0 (GraphPad Software, Inc.). All analytical data were obtained from three independent experimental repeats. Unpaired Student's t-test was used to compare the difference between two groups, whereas comparisons among multiple groups were analyzed using one-way ANOVA followed by Tukey's post hoc test. $\mathrm{P}<0.05$ was considered to indicate a statistically significant difference.

\section{Results}

BBR alleviates PA-induced podocyte death and apoptosis. According to our previous study, PA at a concentration of $150 \mu \mathrm{mol} / 1$ induced marked lipid accumulation and apoptosis of podocytes (22); therefore, $150 \mu \mathrm{mol} / 1 \mathrm{PA}$ was selected in the present study to treat podocytes. To evaluate the effects of BBR on PA-induced cell death, podocytes were treated with PA and different concentrations of BBR for $24 \mathrm{~h}$. Using the CCK-8 cell viability assay, a significant increase in podocyte death was observed in the PA group compared with in the control group, whereas a significant amelioration of PA-induced cell death was observed when cells were pretreated with BBR at a concentration of 4,8 and $16 \mu \mathrm{mol} / 1$ (Fig. 1A). Podocytes pretreated 
A

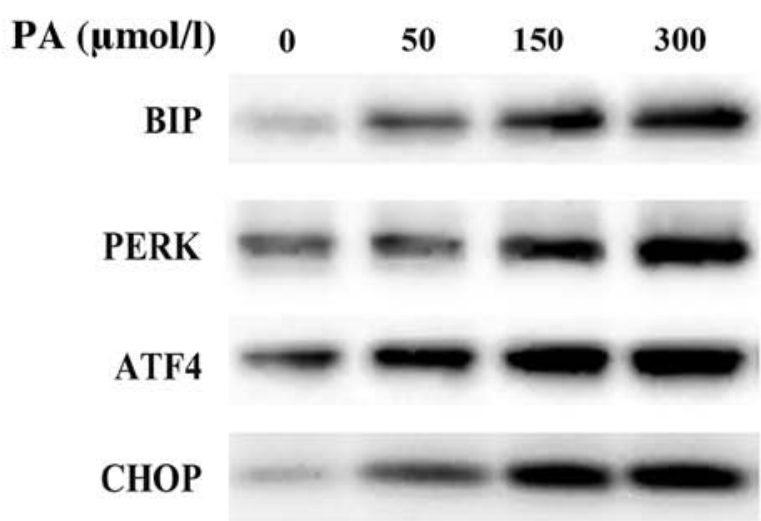

ATF6

IRE1 $\alpha$

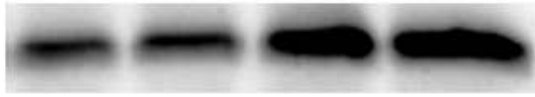

$\beta$-actin

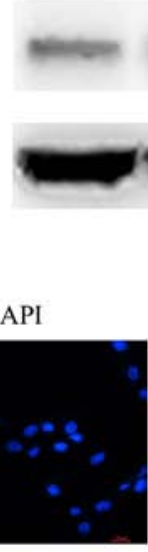

H
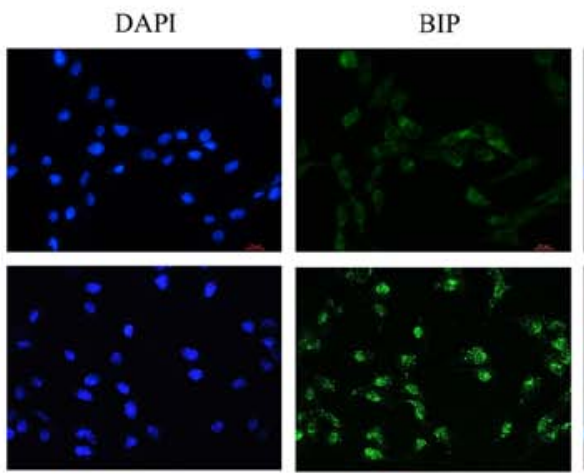

B
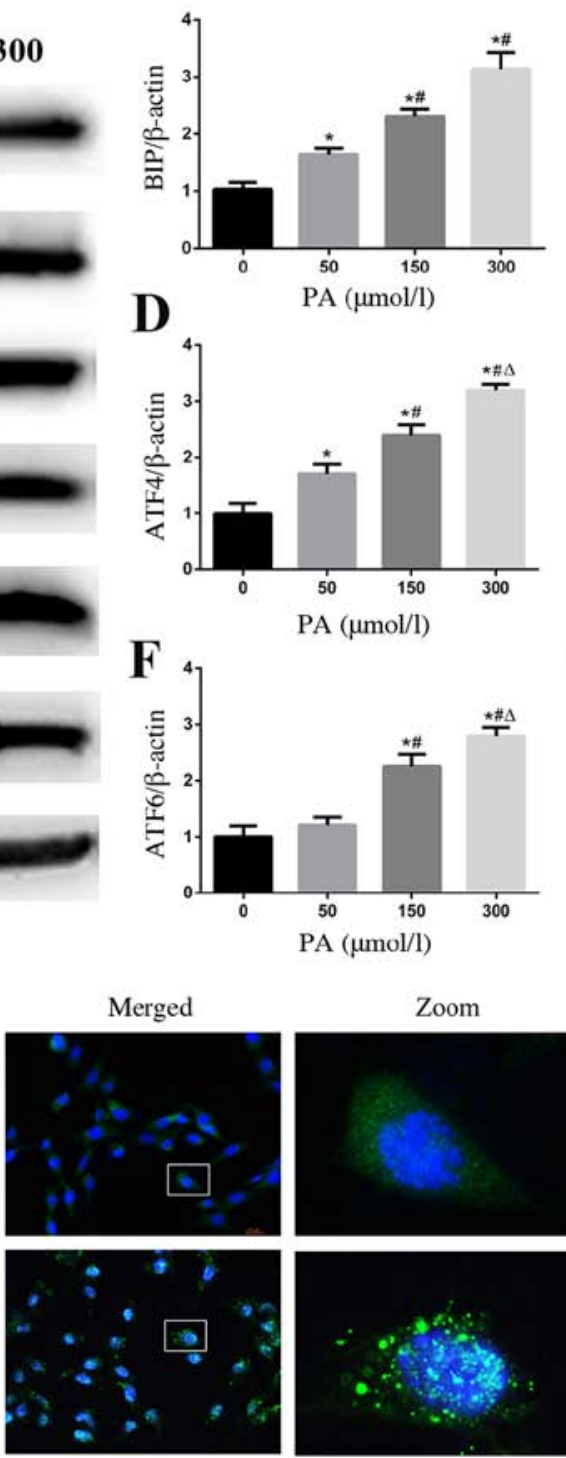

C
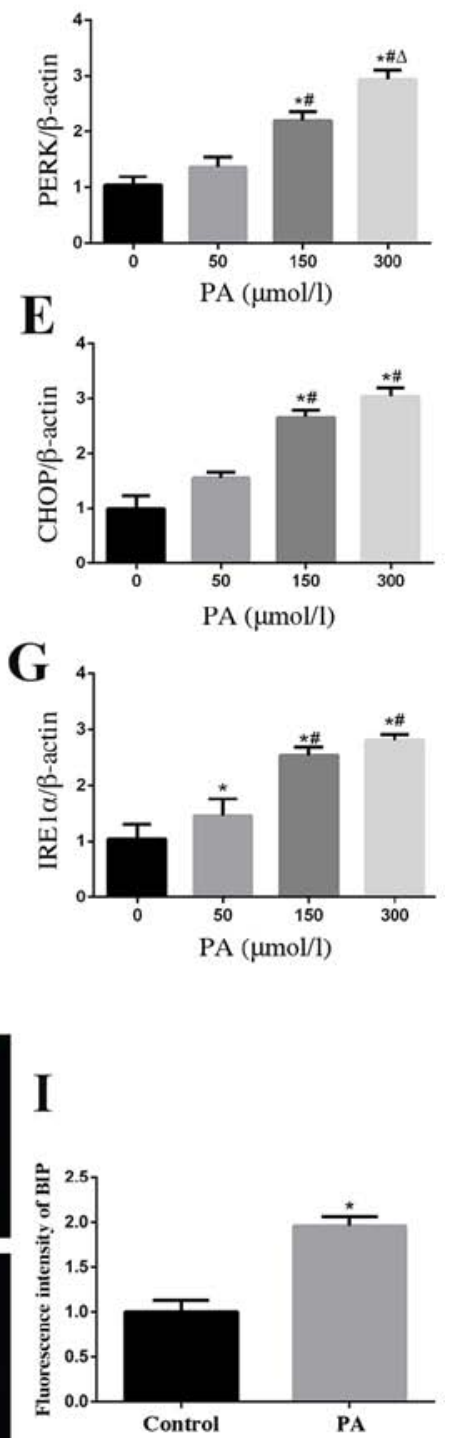

Figure 2. PA induces endoplasmic reticulum stress in podocytes. (A) Representative images of BIP, PERK, ATF4, CHOP, ATF6 and IRE1 $\alpha$ expression, as detected by western blot analysis after treatment with different concentrations of PA. Densitometric analysis of the results shown in (A) for (B) BIP, (C) PERK, (D) ATF4, (E) CHOP, (F) ATF6 and (G) IRE1 $\alpha$. Data are presented as the mean \pm SEM (n=3). ${ }^{*} \mathrm{P}<0.05$ vs. $0 \mu$ mol/1 group, ${ }^{\#} \mathrm{P}<0.05$ vs. $50 \mu$ mol/1 group, ${ }^{\Delta} \mathrm{P}<0.05$ vs. $150 \mu \mathrm{mol} / 1$ group. (H) BIP expression was detected by fluorescence microscopy after the cells had been treated with PA (150 $\mu$ mol/1) for $24 \mathrm{~h}$ (magnification, x400). The rightmost panels show the enlarged (x7) views of areas in the left panels. (I) Fluorescence intensities of five random fields per group, as shown in $(\mathrm{H})$, were determined and analyzed. Data are presented as the mean $\pm \mathrm{SEM}$ ( $\mathrm{n}=3$ ). * $\mathrm{P}<0.05$ vs. control group. PA, palmitic acid; BIP, binding immunoglobulin protein; PERK, protein kinase RNA-like endoplasmic reticulum kinase; ATF, activating transcription factor; CHOP, C/EBP homologous protein; IRE1 $\alpha$, inositol-requiring enzyme 1 $\alpha$; SEM, standard error of the mean.

with $8 \mu \mathrm{mol} / 1 \mathrm{BBR}$ had a higher survival rate than those in the other treatment groups. Therefore, the suitable concentration of BBR to treat podocytes in further experiments was considered to be $8 \mu \mathrm{mol} / 1$ (Fig. 1A). Cleaved-caspase 3 is an important marker of apoptosis, which is one of the main types of cell death (22). The expression levels of cleaved-caspase 3 were detected using western blotting (Fig. 1B and D) and apoptotic rate was assessed by flow cytometry (Fig. 1C and E); the results confirmed that PA induced podocyte apoptosis and BBR alleviated PA-induced podocyte apoptosis.

$P A$ induces ER stress in podocytes. When ER stress occurs, the ER aims to maintain a stable cellular environment by increasing the ER capacity and activating the ER-associated protein degradation pathway (23). The ER chaperone BIP, also known as glucose-regulated protein 78 , has an important role in protein folding. Dissociation of BIP from ER-bound sensors, such as PERK, IRE1 $\alpha$ and ATF6, to bind unfolded or misfolded proteins is the consequence of ER stress, which can regulate the transcription of BIP to increase the ER capacity $(24,25)$. To explore whether ER stress may be involved in PA-induced podocyte apoptosis, western blotting was used to detect the protein expression levels of BIP. The results revealed that $\mathrm{PA}$ treatment increased the expression of BIP in a concentration-dependent manner (Fig. 2A and B). A similar finding regarding BIP expression in podocytes following PA treatment was confirmed by immunofluorescent staining (Fig. $2 \mathrm{H}$ and I). Furthermore, the protein 


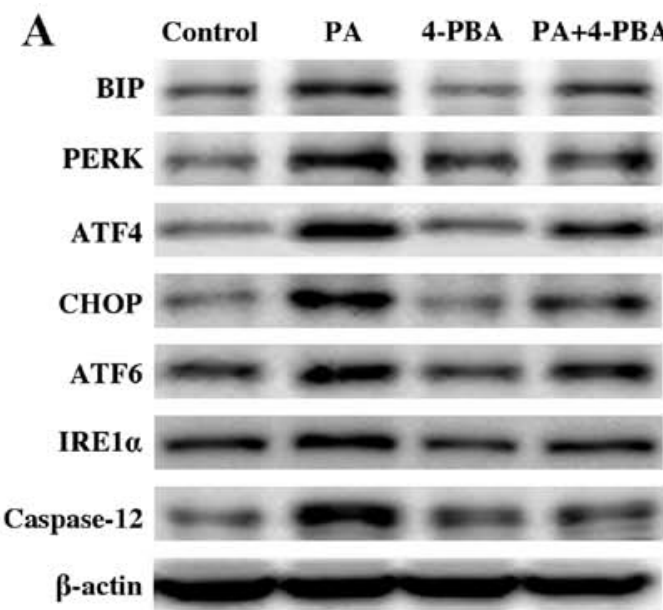

B

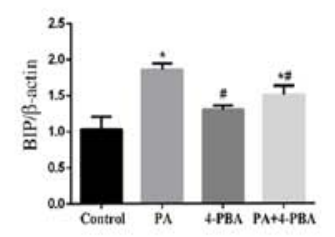

D

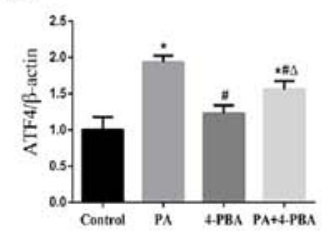

C

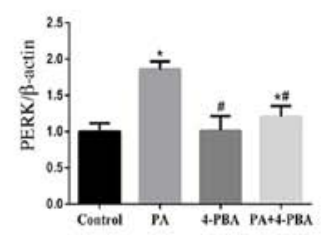

E

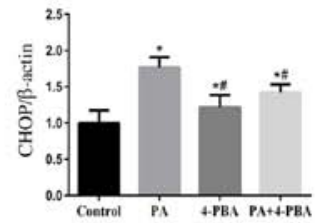

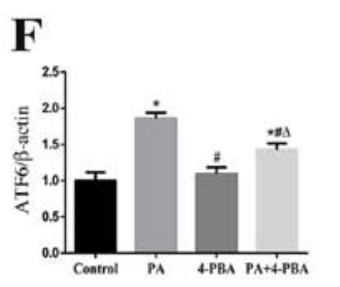

G

\section{H}
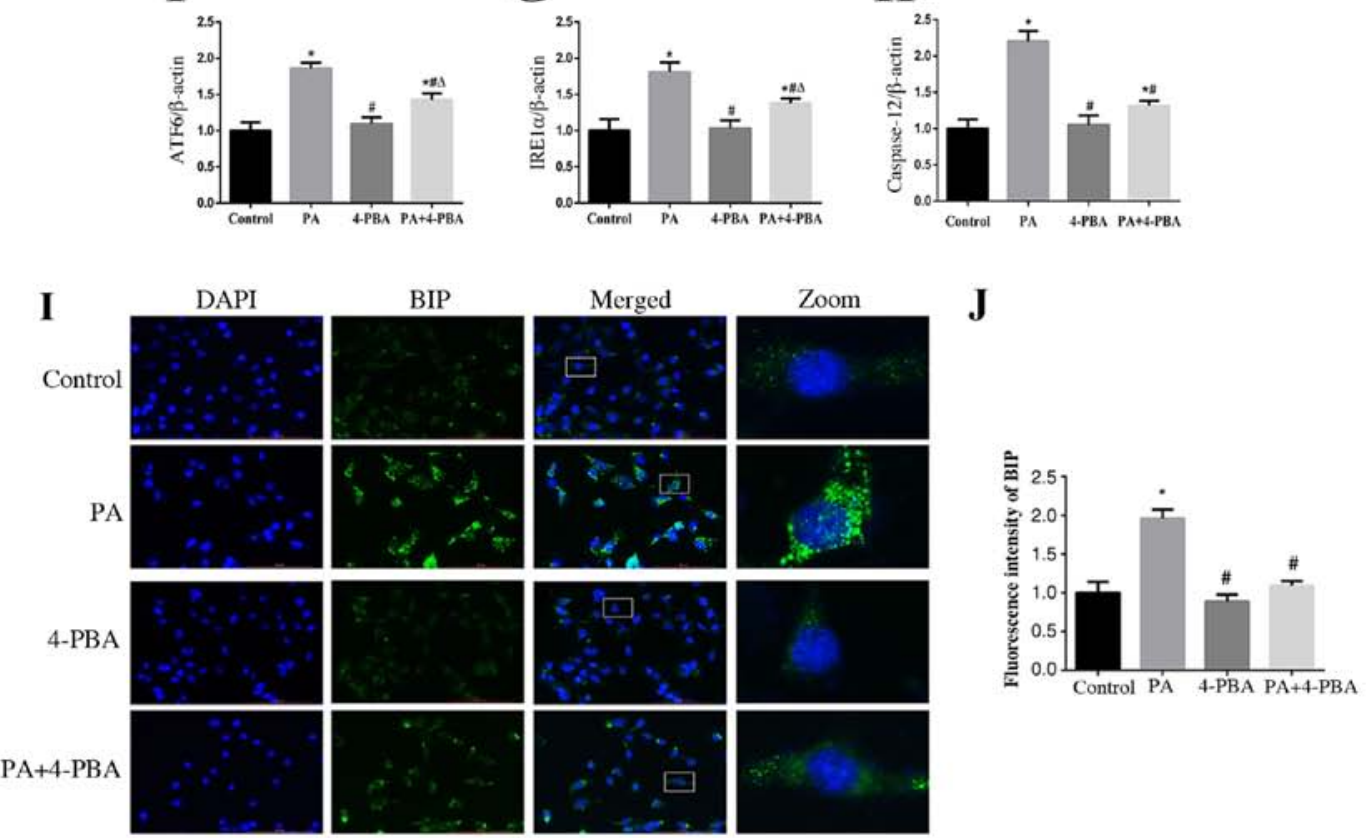

K
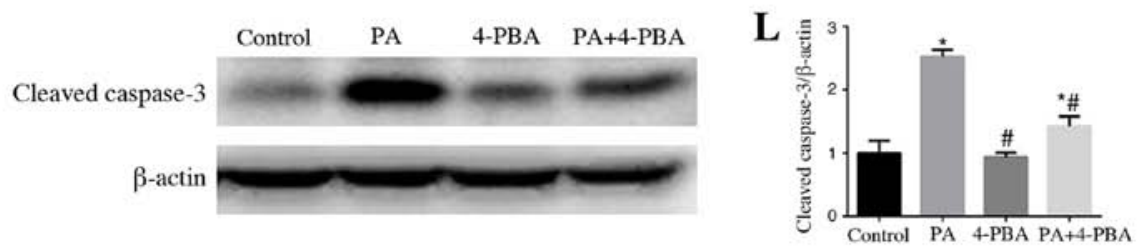

M

$\mathbf{N}$
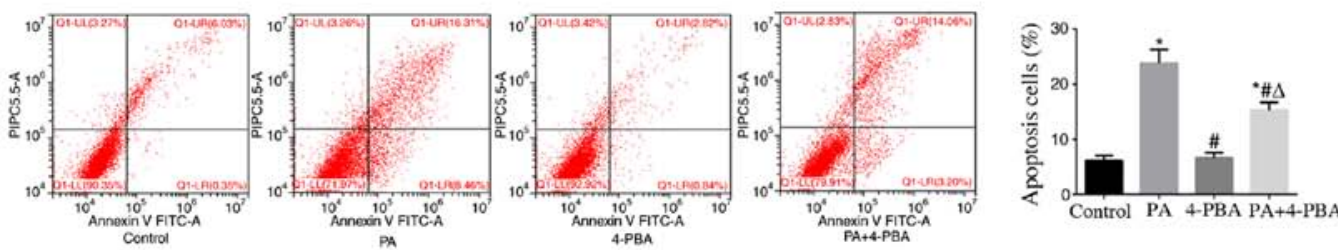

Figure 3. Endoplasmic reticulum stress is involved in PA-induced apoptosis of podocytes. (A) Representative images of BIP, PERK, ATF4, CHOP, ATF6, IRE1 $\alpha$ and caspase 12 expression, as detected by western blot analysis after treatment with PA (150 $\mu \mathrm{mol} / \mathrm{l})$ and/or 4-PBA (10 $\mu$ mol/l). $\beta$-actin was used as a loading control. Densitometric analysis of the data shown in (A) for (B) BIP, (C) PERK, (D) ATF4, (E) CHOP, (F) ATF6, (G) IRE1 $\alpha$ and (H) caspase 12. Data are presented as the mean $\pm \operatorname{SEM}(\mathrm{n}=3)$. ${ }^{*} \mathrm{P}<0.05$ vs. control group, ${ }^{*} \mathrm{P}<0.05$ vs. PA group, ${ }^{\wedge} \mathrm{P}<0.05$ vs. 4 -PBA group. (I) Cells were treated with PA (150 $\mu$ mol/l) for $24 \mathrm{~h}$ after pretreatment with or without 4-PBA $(10 \mu \mathrm{mol} / \mathrm{l})$ for $2 \mathrm{~h}$ and BIP expression was measured by fluorescence microscopy (magnification, $\mathrm{x} 400)$. The rightmost panels show the enlarged views (x7) of areas in the left panels. (J) Fluorescence intensities of five randomly selected fields per group, as shown in (I), were determined and analyzed. Data are presented as the mean \pm SEM $(n=3) .{ }^{~} \mathrm{P}<0.05$ vs. control group, ${ }^{\prime} \mathrm{P}<0.05$ vs. PA group. (K) Representative images of cleaved-caspase 3 expression, as measured by western blot analysis. (L) Densitometric analysis of the cleaved-caspase 3 expression shown in (K). (M) Representative plots of apoptosis determined by flow cytometry. (N) Quantitative analysis of the results shown in (M). Data are presented as the mean \pm SEM $(n=3)$. " $P<0.05$ vs. control group, ${ }^{\#} P<0.05$ vs. $P A$ group, ${ }^{\Delta} \mathrm{P}<0.05$ vs. 4-PBA group. PA, palmitic acid; 4-PBA, 4-phenyl butyric acid; BIP, binding immunoglobulin protein; PERK, protein kinase RNA-like endoplasmic reticulum kinase; ATF, activating transcription factor; CHOP, C/EBP homologous protein; IRE1 $\alpha$, inositol-requiring enzyme $1 \alpha$; SEM, standard error of the mean. 
expression levels of PERK, ATF4, CHOP, IRE1 $\alpha$ and ATF6, which are involved in the ER stress-mediated pathway, were also increased (Fig. 2A and C-G). These findings indicated that ER stress and its three downstream signaling pathways (PERK, IRE1 $\alpha$ and ATF6) may be activated by PA treatment in podocytes.

ER stress is involved in PA-induced apoptosis of podocytes. To further validate the role of ER stress in PA-induced apoptosis, podocytes were treated with $10 \mu \mathrm{mol} / \mathrm{l} 4$-PBA, an ER stress inhibitor, with or without PA $(150 \mu \mathrm{mol} / \mathrm{l})$ for $24 \mathrm{~h}$. The results of western blotting revealed that treatment with 4-PBA ameliorated PA-induced expression of proteins associated with the three downstream signaling pathways (Fig. 3A-G). In addition, decreased signal intensity of BIP in podocytes treated with 4-PBA was observed compared with that exhibited following treatment with PA only, as determined using immunofluorescent staining (Fig. 3I and J). These results suggested that 4-PBA may alleviate ER stress induced by PA in podocytes. Furthermore, an ER stress-associated apoptosis indicator, caspase 12 , was significantly downregulated by 4-PBA in PA-treated podocytes (Fig. 3A and H). Furthermore, the expression of cleaved-caspase 3 (Fig. $3 \mathrm{~K}$ and L) and PA-induced podocyte apoptosis was significantly decreased (Fig. 3M and N) when cells were treated with 4-PBA. These results suggested that ER stress may participate in PA-induced podocyte apoptosis.

Role of oxidative stress in PA-induced ER stress and apoptosis in podocytes. Using DCFH-DA staining, a sensitive fluorescent probe to detect cellular ROS, it was confirmed that PA enhanced ROS generation in a concentration-dependent manner (Fig. 4A and B). However, treatment with NAC, a ROS scavenger, significantly reduced the ROS production induced by PA in podocytes (Fig. $4 \mathrm{C}$ and D). To further clarify the role of oxidative stress in PA-induced ER stress, the expression levels of ER stress-associated proteins were detected by western blotting in podocytes following treatment with PA in the presence or absence of NAC. The results revealed that the expression levels of BIP, PERK, ATF4, CHOP, IRE1 $\alpha$, ATF6 and caspase-12 induced by PA were suppressed by NAC (Fig. 4E-L), which indicated that PA-induced ER stress may be dependent on oxidative stress. Moreover, treatment with NAC alleviated PA-induced podocyte apoptosis (Fig. 4M-P), which suggested that oxidative stress served a crucial role in PA-induced podocyte apoptosis.

BBR improves PA-induced ER stress and oxidative stress in podocytes. To investigate the role of BBR in PA-induced ER stress and oxidative stress, podocytes were treated with PA $(150 \mu \mathrm{mol} / \mathrm{l})$ and were pretreated with BBR $(8 \mu \mathrm{mol} / \mathrm{l})$. The results demonstrated that BBR suppressed PA-induced ER stress in podocytes (Fig. 5A-H). Immunofluorescence staining also revealed that BIP expression (Fig. 5I and J) and intracellular ROS production (Fig. 5K and L) were decreased in podocytes following treatment with BBR compared with in the PA group. These findings suggested that BBR may alleviate the ROS-dependent ER stress induced by PA in podocytes.

\section{Discussion}

Patients with CKD often present with dyslipidemia at both the early stages of renal dysfunction and at end-stage renal disease. Lipid abnormalities in turn accelerate CKD progression and the development of associated comorbidities $(1,26,27)$. Hence, lipid-lowering therapy has become one of the beneficial therapeutic strategies for CKD (28). Podocytes are important components of the kidney glomerulus and are crucial to maintain the integrity of kidney filtration; however, podocytes are highly susceptible to FFAs or an altered lipid environment. Podocyte dysfunction and apoptosis caused by altered dyslipidemia has been reported to contribute to the initiation and progression of CKD $(29,30)$. The present study confirmed that PA may induce podocyte cell death and apoptosis.

BBR is a traditional treatment applied in gastrointestinal diseases, such as diarrhea, which has numerous pharmacological effects, including anti-inflammatory (31), antioxidant (32) and anticancer $(31,33)$ effects. Numerous studies have assessed the effects of BBR on hyperglycemia and dyslipidemia $(17,34)$. Previous studies demonstrated that BBR inhibited kidney damage in high-fat diet-fed rats (35) and DN in the clinic (18). In addition, it has been reported that BBR may exert a protective effect on hepatocytes and the liver in high-fat diet-fed mice by alleviating oxidative stress and ER stress $(19,36)$. A recent study revealed that BBR could protect podocytes from injury and apoptosis induced by FFAs by regulating Drp1-mediated mitochondrial function (37). The present findings also indicated that BBR had a robust protective effect against PA-induced podocyte apoptosis. Notably, it was observed that in PA-stimulated podocytes pretreated with $8 \mu \mathrm{mol} / 1 \mathrm{BBR}$ there was a higher cell survival ratio than in those pretreated with $16 \mu \mathrm{mol} / 1 \mathrm{BBR}$. These data indicated that the protective effect of BBR may be related to its dosage, and it could potentially damage podocytes when the dosage reaches a high concentration. However, the underlying protective mechanism is complex and further research is required to clarify it.

The ER is an extensive, interconnected series of membranous sacs present in eukaryotic cells. The majority of secreted and transmembrane proteins are translocated into the lumen of the ER to undergo protein modification and folding. An accumulation of unfolded proteins or misfolded proteins in the ER leads to ER stress (38). To mitigate such circumstances, BIP, an ER-resident molecular chaperon, detaches from three transmembrane ER stress sensors, IREI, PERK and ATF6, and activates a homeostatic intracellular signaling network to alleviate ER stress, which is known as the unfolded protein response (UPR) $(23,38,39)$. Among these proteins, PERK can phosphorylate the eukaryotic translation initiation factor eIF $2 \alpha$ to prevent proteins from entering the ER, encoding the transcription factor ATF4 to activate downstream UPR target genes and $\mathrm{CHOP}$, which are involved in apoptosis $(40,41)$. A moderate UPR can help to recover ER homeostasis; however, severe or prolonged stress ultimately leads to cell apoptosis $(23,41)$. It has been reported that ER stress can be stimulated in adipose tissue in high-fat diet-induced obese mice (42), and ER stress participates in neurodegenerative, endocrine and various renal diseases (43-45). In the current study, PA increased 

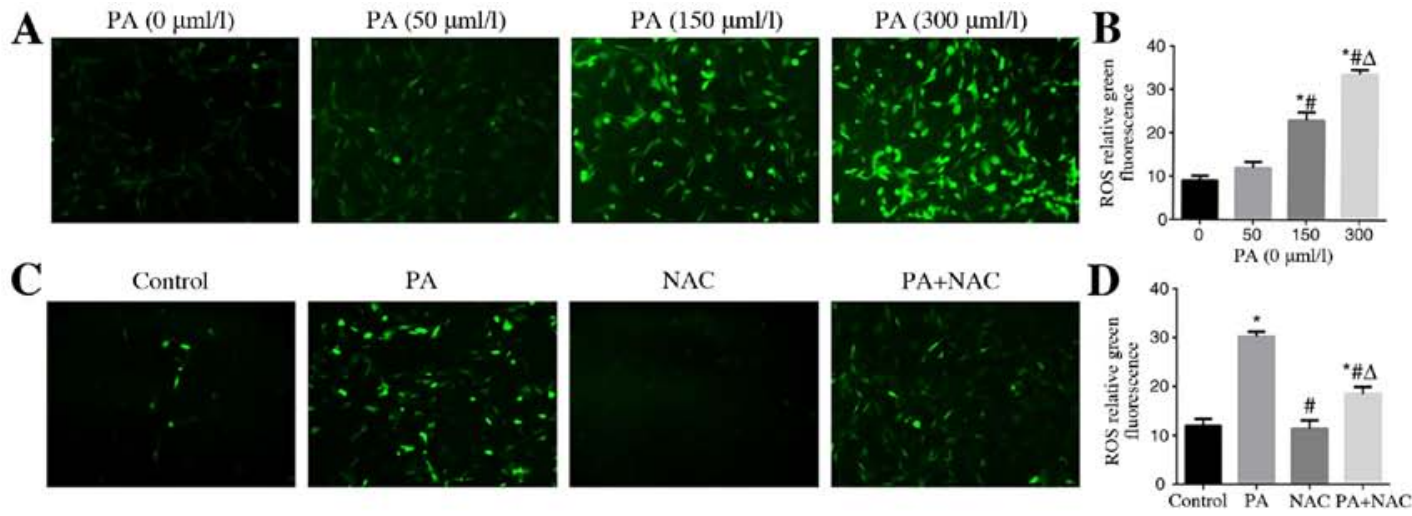

$\mathbf{E}$

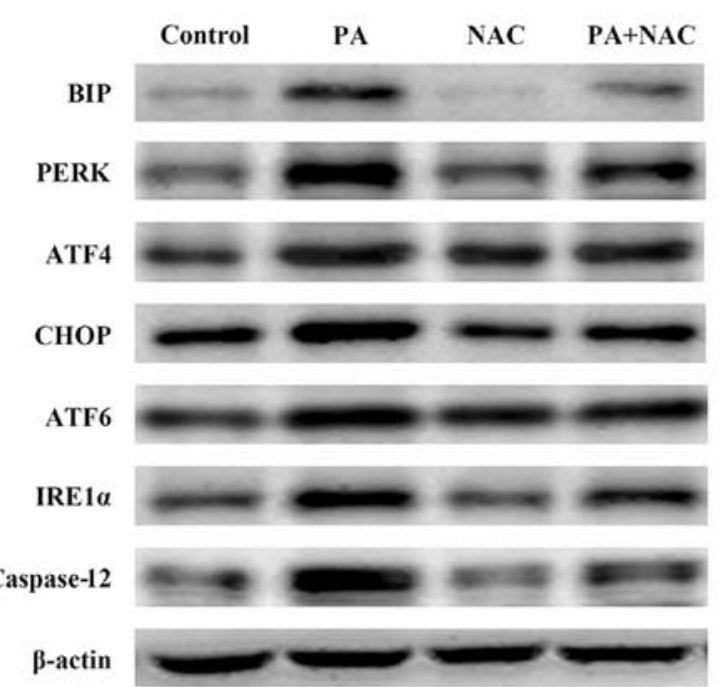

F

G
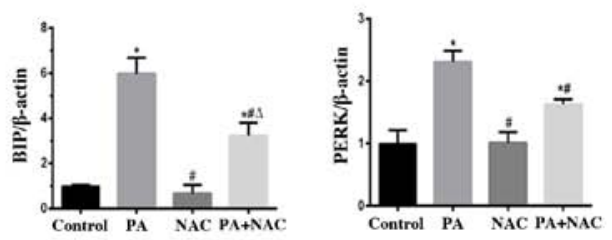

\section{$\mathbf{H}$}

\section{I}
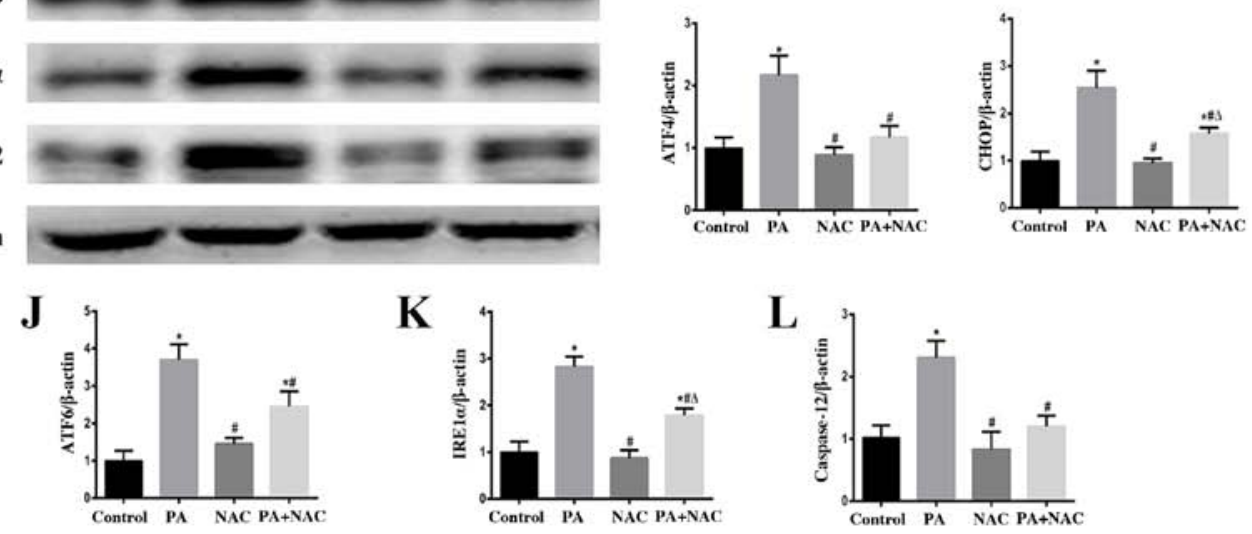

M
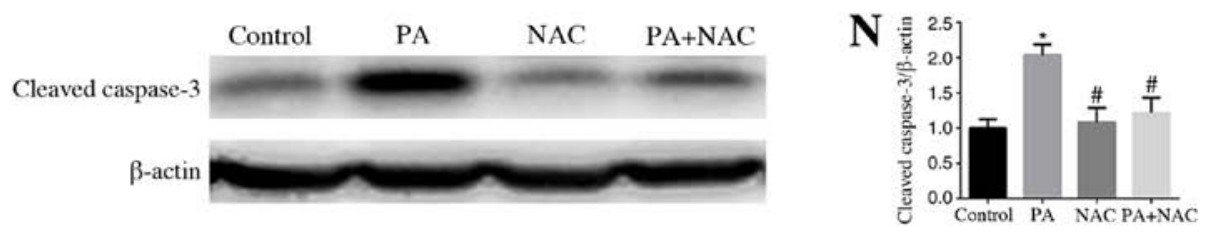

$\mathbf{O}$

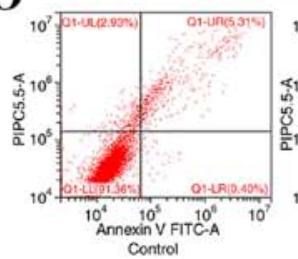

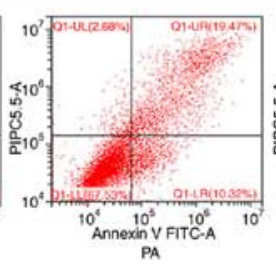

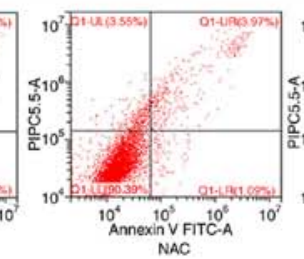

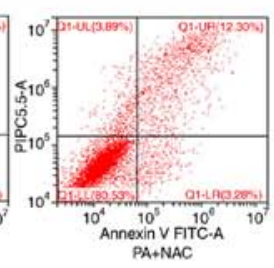

Figure 4. Role of oxidative stress in PA-induced endoplasmic reticulum stress and apoptosis in podocytes. (A and C) Representative immunofluorescence images of intracellular ROS in podocytes (magnification, x200) following treatment with different concentrations of PA, or PA (150 $\mu$ mol/l) for $24 \mathrm{~h}$ after pretreatment with or without NAC $(150 \mu \mathrm{mol} / \mathrm{l})$ for $2 \mathrm{~h}$. (B) Mean fluorescence intensities of ROS shown in (A). Data are presented as the mean \pm SEM ( $=3)$. ${ }^{*}<0.05$ vs. PA $(0 \mu \mathrm{mol} / \mathrm{l})$ group, ${ }^{\#} \mathrm{P}<0.05$ vs. PA $(50 \mu \mathrm{mol} / \mathrm{l})$ group, ${ }^{\Delta} \mathrm{P}<0.05 \mathrm{vs}$. PA $(150 \mu \mathrm{mol} / 1)$ group. (D) Mean fluorescence intensities of ROS shown in $(\mathrm{C})$. Data are presented as the mean \pm SEM $(n=3)$. ${ }^{*} \mathrm{P}<0.05$ vs. control group, ${ }^{\#} \mathrm{P}<0.05$ vs. PA group, ${ }^{\Delta} \mathrm{P}<0.05$ vs. NAC group. (E and M) Representative images of BIP, PERK, ATF4, CHOP, ATF6, IRE1 $\alpha$, caspase 12 and cleaved-caspase 3 expression, as detected by western blotting after treatment with PA (150 $\mu$ mol/l) or NAC (150 $\mu$ mol/1). $\beta$-actin was used as a loading control. Densitometric analysis of the data shown in (E and M) for (F) BIP, (G) PERK, (H) ATF4, (I) CHOP, (J) ATF6, (K) IRE1 $\alpha$, (L) caspase 12 and $(\mathrm{N})$ cleaved-caspase 3 . Data are presented as the mean $\pm \mathrm{SEM}(\mathrm{n}=3) .{ }^{*} \mathrm{P}<0.05$ vs. control group, ${ }^{*} \mathrm{P}<0.05$ vs. $\mathrm{PA}$ group, ${ }^{\Delta} \mathrm{P}<0.05$ vs. $\mathrm{NAC}$ group. (O) Representative plots of podocyte apoptosis evaluated by flow cytometry after treatment with PA (150 $\mu$ mol/l) and NAC (150 $\mu$ mol/l) for $24 \mathrm{~h}$. (P) Quantification of podocyte apoptosis shown in (O). Data are presented as the mean $\pm \mathrm{SEM}(\mathrm{n}=3) .{ }^{*} \mathrm{P}<0.05$ vs. control group, ${ }^{\#} \mathrm{P}<0.05$ vs. PA group, ${ }^{\Delta} \mathrm{P}<0.05$ vs. NAC group. PA, palmitic acid; ROS, reactive oxygen species; NAC, N-acetylcysteine; BIP, binding immunoglobulin protein; PERK, protein kinase RNA-like endoplasmic reticulum kinase; ATF, activating transcription factor; CHOP, C/EBP homologous protein; IRE1 $\alpha$, inositol-requiring enzyme 1 $\alpha$; SEM, standard error of the mean. 

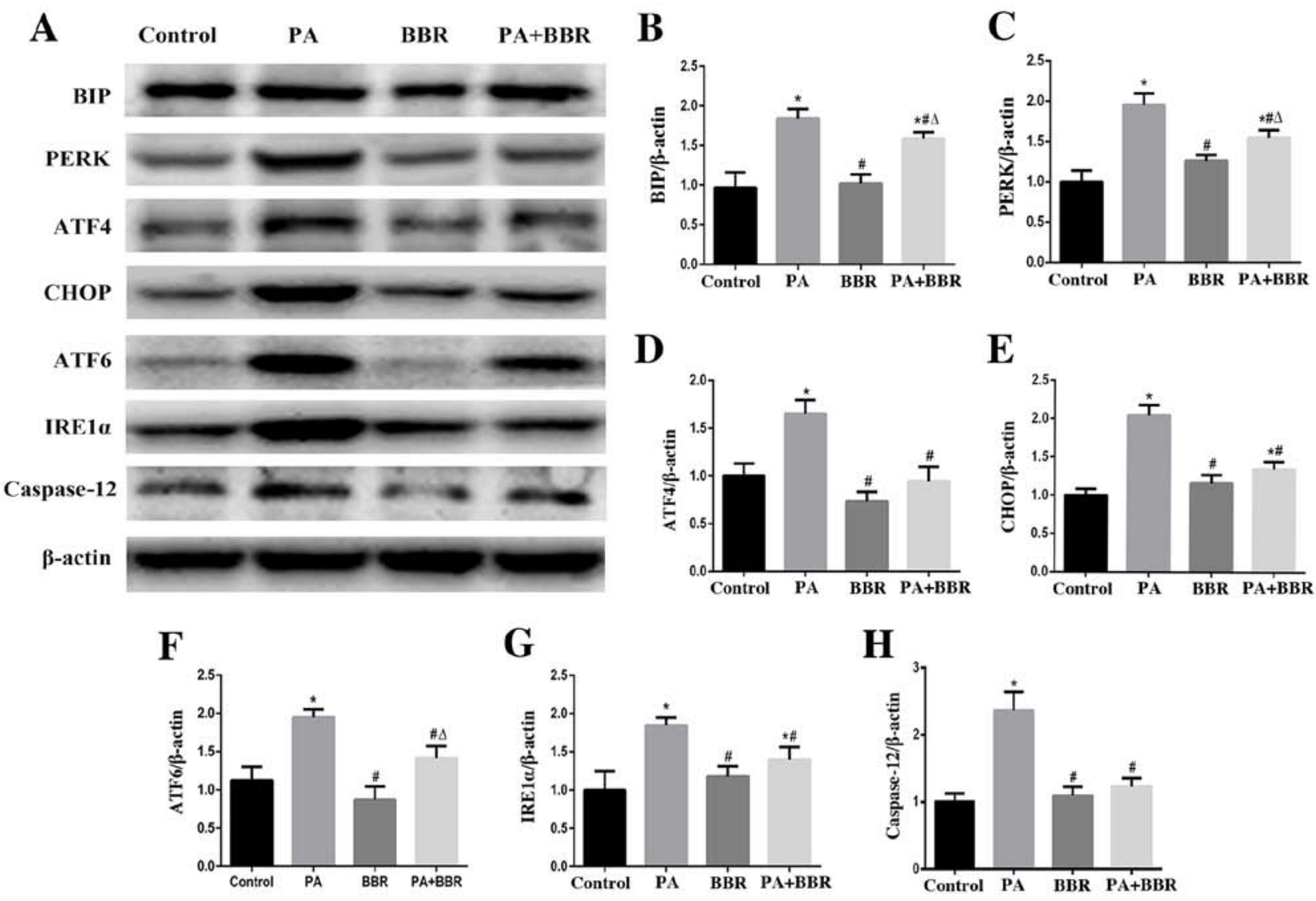

I
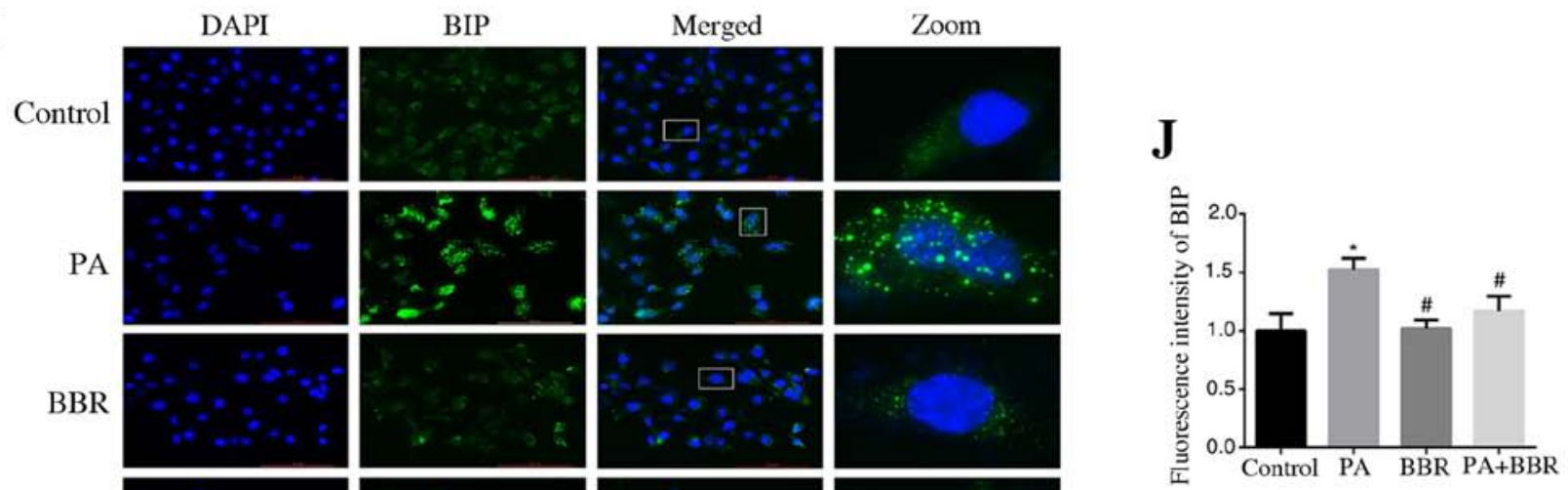

$\mathrm{PA}+\mathrm{BBR}$
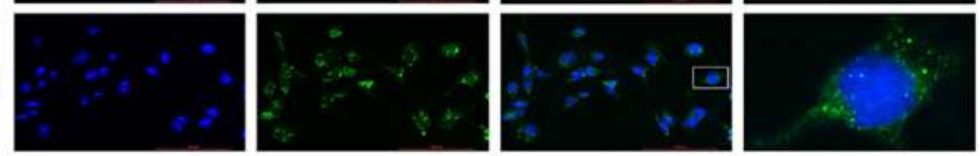

$\mathbf{K}$
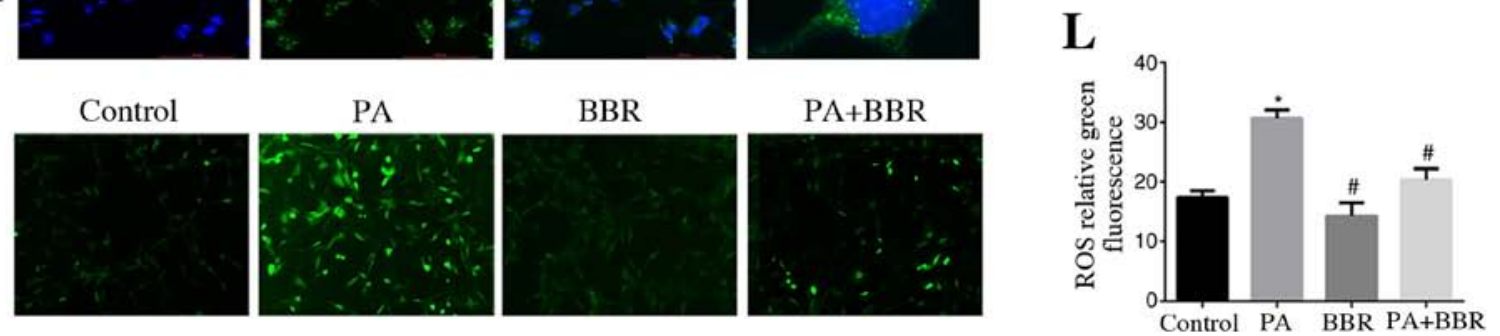

Figure 5. BBR improves PA-induced endoplasmic reticulum stress and oxidative stress in podocytes. (A) Representative images of BIP, PERK, ATF4, CHOP, ATF6, IRE1 $\alpha$ and caspase 12 expression, as detected by western blot analysis after treatment with PA $(150 \mu \mathrm{mol} / \mathrm{l})$ for $24 \mathrm{~h}$ after pretreated with BBR $(8 \mu \mathrm{mol} / \mathrm{l})$ for $2 \mathrm{~h}$. $\beta$-actin was expressed as an internal control. Densitometric analysis of the results shown in (A) for (B) BIP, (C) PERK, (D) ATF4, (E) CHOP, (F) ATF6, (G) IRE1 $\alpha$ and $(\mathrm{H})$ caspase 12. Data are presented as the mean $\pm \mathrm{SEM}(\mathrm{n}=3)$. ${ }^{*} \mathrm{P}<0.05$ vs. control group, ${ }^{*} \mathrm{P}<0.05$ vs. $\mathrm{PA}$ group, ${ }^{\Delta} \mathrm{P}<0.05$ vs. $\mathrm{BBR}$ group. (I) BIP expression was verified by fluorescence microscopy following treatment of cells with PA $(150 \mu \mathrm{mol} / \mathrm{l})$ for $24 \mathrm{~h}$ after pretreatment with or without $\operatorname{BBR}(8 \mu \mathrm{mol} / 1)$ for $2 \mathrm{~h}$ (magnification, $\mathrm{x} 400)$. The rightmost panels show the enlarged views (x7) of areas in the left panels. (J) Fluorescence intensities of five randomly selected fields in each group (as shown in panel I) were determined and analyzed. Data are presented as the mean \pm SEM $(n=3)$. " $P<0.05$ vs. control group, ${ }^{\#} \mathrm{P}<0.05$ vs. PA group. (K) Representative immunofluorescence images of intracellular ROS in podocytes by fluorescence microscopy (magnification, $\mathrm{x} 200)$ following treatment with PA $(150 \mu \mathrm{mol} / \mathrm{l})$ for $24 \mathrm{~h}$ in the presence or absence of BBR $(8 \mu \mathrm{mol} / \mathrm{l})$ for $2 \mathrm{~h}$. (L) Mean fluorescence intensities of the ROS shown in $(\mathrm{K})$. Data are expressed as the mean $\pm \mathrm{SEM}(\mathrm{n}=3)$. " $\mathrm{P}<0.05$ vs. control group, ${ }^{\#} \mathrm{P}<0.05$ vs. PA group. BBR, berberine; BIP, binding immunoglobulin protein; PERK, protein kinase RNA-like endoplasmic reticulum kinase; ATF, activating transcription factor; CHOP, C/EBP homologous protein; IRE1 $\alpha$, inositol-requiring enzyme $1 \alpha$. 
cell apoptosis and upregulated ER stress-related proteins, including activation of caspase 12, which is one of the two main signaling proteins of ER stress-induced apoptosis (46). Conversely, 4-PBA, an ER stress inhibitor, downregulated ER stress, and inhibited PA-induced expression of caspase 12 and podocyte apoptosis. Therefore, these findings suggested that ER stress participated in PA-induced podocyte apoptosis.

Oxidative stress, which is mediated by ROS, has been reported to serve a role in the pathophysiology of renal impairment and in the progression of CKD (47). Excessive FFAs can cause podocyte injury by boosting the production of ROS and lipid peroxidation, which contribute to glomerular lesions (48). ROS and ER stress often occur together, and ROS overproduction may lead to ER stress $(48,49)$. Exogenous ROS can disturb ER protein folding, activate some aspects of the UPR and induce ER stress (49-51). On the other hand, oxidative stress can be strengthened by protein misfolding in the ER (51). In the present study, PA induced an increase in intracellular ROS, whereas NAC, an antioxidant reagent, reduced ROS production, and attenuated ER stress and podocyte apoptosis induced by PA, thus demonstrating that the ROS-ER stress signaling pathway may be a key mechanism in podocyte apoptosis induced by PA. Furthermore, it was observed that treatment with BBR reduced ROS generation and inhibited the ER stress in PA-treated podocytes. Similarly, it was previously reported that BBR could alleviate ER stress induced by hypoxia/reoxygenation injury in HK-2 cells (52). Moreover, Zhu et al (53) demonstrated that BBR ameliorated the development of DN via inactivating the TLR4/NF- $\kappa B$ pathway. A recent review elaborated that the efficacy of BBR for treating multiple diseases was mediated by its multi-target pharmacological profile; its molecular targets include AMPK, PTP1B, SIRT1, PCSK9, LDLR, PPAR and NF- $\mathrm{KB}$, and that modulation of gut microbiota was involved in the metabolic effects of BBR (54). However, the direct molecular target remains unclear. Taken together, the present findings indicated that BBR alleviated podocyte apoptosis via inhibition of the ROS-mediated ER stress pathway. However, the mechanism by which BBR specifically regulates ROS mediated-ERS and the direct molecular target of BBR require further investigation in vivo.

In conclusion, the present study demonstrated that ER stress and increased production of ROS may be the key mechanism underlying PA-induced podocyte apoptosis. BBR may protect against PA-induced podocyte apoptosis by suppressing ROS-dependent ER stress. However, further studies, such as using reverse transcription-quantitative PCR, are required to confirm the mechanism of regulation of BBR. In addition, this was an in vitro study, and further studies using an in vivo model are needed to support these results.

\section{Acknowledgements}

Not applicable.

\section{Funding}

This study was supported by the National Natural Science Foundation of China (grant no. 81370816) and the Natural Science Foundation of Chongqing Science and Technology Commission of China (grant no. cstc2012jjA10136).

\section{Availability of data and materials}

The datasets used and/or analyzed during the current study are available from the corresponding author on reasonable request.

\section{Authors' contributions}

XYX and TL performed the experiments, analyzed the data and wrote the manuscript. XMC and YW participated in study design and data interpretation, and were responsible for the overall direction of this work. JLH and XSJ contributed to analyzing and interpreting the data, drafting the manuscript and revising it critically for important intellectual content. XGD analyzed the results, supervised the project and gave final approval of the version to be published. All authors read and approved the final manuscript.

\section{Ethics approval and consent to participate}

Not applicable.

\section{Patient consent for publication}

Not applicable.

\section{Competing interests}

The authors declare that they have no competing interests.

\section{References}

1. Hager MR, Narla AD and Tannock LR: Dyslipidemia in patients with chronic kidney disease. Rev Endocr Metab Disord 18: 29-40, 2017.

2. Keane WF, Tomassini JE and Neff DR: Lipid abnormalities in patients with chronic kidney disease: Implications for the pathophysiology of atherosclerosis. J Atheroscler Thromb 20: 123-133, 2013.

3. Kasiske BL and Wheeler DC: The management of dyslipidemia in CKD: New analyses of an expanding dataset. Am J Kidney Dis 61: 371-374, 2013.

4. Kowalski A, Krikorian A and Lerma EV: Dyslipidemia in chronic kidney disease. Dis Mon 61: 396-402, 2015.

5. Izquierdo-Lahuerta A, Martinez-Garcia C and Medina-Gómez G: Lipotoxicity as a trigger factor of renal disease. J Nephrol 29: 603-610, 2016.

6. Dai H, Liu Q and Liu B: Research progress on mechanism of podocyte depletion in diabetic nephropathy. J Diabetes Res 2017: 2615286, 2017.

7. Dalla Vestra M, Masiero A, Roiter AM, Saller A, Crepaldi G and Fioretto P: Is podocyte injury relevant in diabetic nephropathy? Studies in patients with type 2 diabetes. Diabetes 52: 1031-1035, 2003.

8. Zhang Y, Ma KL, Liu J, Wu Y, Hu ZB, Liu L and Liu BC: Dysregulation of low-density lipoprotein receptor contributes to podocyte injuries in diabetic nephropathy. Am J Physiol Endocrinol Metab 308: E1140-E1148, 2015.

9. Szeto HH, Liu S, Soong Y, Alam N, Prusky GT and Seshan SV: Protection of mitochondria prevents high-fat diet-induced glomerulopathy and proximal tubular injury. Kidney Int 90: 997-1011, 2016.

10. Martinez-Garcia C, Izquierdo-Lahuerta A, Vivas Y, Velasco I, Yeo TK, Chen S and Medina-Gomez G: Renal lipotoxicity-associated inflammation and insulin resistance affects actin cytoskeleton organization in podocytes. PLoS One 10: e0142291, 2015.

11. Xu S, Nam SM, Kim JH, Das R, Choi SK, Nguyen TT, Quan X, Choi SJ, Chung CH, Lee EY, et al: Palmitate induces ER calcium depletion and apoptosis in mouse podocytes subsequent to mitochondrial oxidative stress. Cell Death Dis 6: e1976, 2015. 
12. .Tao JL, Wen YB, Shi BY, Zhang H, Ruan XZ, Li H, Li XM, Dong WJ and Li XW: Endoplasmic reticulum stress is involved in podocyte apoptosis induced by saturated fatty acid palmitate. Chin Med J (Engl) 125: 3137-3142, 2012.

13. Hua W, Huang HZ, Tan LT, Wan JM, Gui HB, Zhao L, Ruan XZ, Chen XM and Du XG: CD36 mediated fatty acid-induced podocyte apoptosis via oxidative stress. PLoS One 10: e0127507, 2015.

14. Rabbani GH, Butler T, Knight J, Sanyal SC and Alam K: Randomized controlled trial of berberine sulfate therapy for diarrhea due to enterotoxigenic Escherichia coli and Vibrio cholerae. J Infect Dis 155: 979-984, 1987.

15. Taylor CE and Greenough WB III: Control of diarrheal diseases Annu Rev Public Health 10: 221-244, 1989.

16. Lan J, Zhao Y, Dong F, Yan Z, Zheng W, Fan J and Sun G Meta-analysis of the effect and safety of berberine in the treatment of type 2 diabetes mellitus, hyperlipemia and hypertension. J Ethnopharmacol 161: 69-81, 2015.

17. Kong W, Wei J, Abidi P, Lin M, Inaba S, Li C, Wang Y, Wang Z, $\mathrm{Si}$ S, Pan $\mathrm{H}$, et al: Berberine is a novel cholesterol-lowering drug working through a unique mechanism distinct from statins. Nat Med 10: 1344-1351, 2004.

18. Ni WJ, Ding HH and Tang LQ: Berberine as a promising anti-diabetic nephropathy drug: An analysis of its effects and mechanisms. Eur J Pharmacol 760: 103-112, 2015.

19. Zhang Z, Li B, Meng X, Yao S, Jin L, Yang J, Wang J, Zhang H, Zhang Z, Cai D, et al: Berberine prevents progression from hepatic steatosis to steatohepatitis and fibrosis by reducing endoplasmic reticulum stress. Sci Rep 6: 20848, 2016.

20. Wang B, Xu X, He X, Wang Z and Yang M: Berberine improved aldo-induced podocyte injury via inhibiting oxidative stress and endoplasmic reticulum stress pathways both in vivo and in vitro. Cell Physiol Biochem 39: 217-228, 2016.

21. Jiang XS, Chen XM, Wan JM, Gui HB, Ruan XZ and Du XG: Autophagy protects against palmitic acid-induced apoptosis in podocytes in vitro. Sci Rep 7: 42764, 2017.

22. Liu T, Chen XM, Sun JY, Jiang XS, Wu Y, Yang S, Huang HZ, Ruan XZ and Du XG: Palmitic acid-induced podocyte apoptosis via the reactive oxygen species-dependent mitochondrial pathway. Kidney Blood Press Res 43: 206-219, 2018

23. Rashid HO, Yadav RK, Kim HR and Chae HJ: ER stress: Autophagy induction, inhibition and selection. Autophagy 11: 1956-1977, 2015.

24. Lukas J, Pospech J, Oppermann C, Hund C, Iwanov K, Pantoom S, Petters J, Frech M, Seemann S, Thiel FG, et al: Role of endoplasmic reticulum stress and protein misfolding in disorders of the liver and pancreas. Adv Med Sci 64: 315-323, 2019.

25. Maamoun H, Abdelsalam SS, Zeidan A, Korashy HM and Agouni A: Endoplasmic reticulum stress: A critical molecular driver of endothelial dysfunction and cardiovascular disturbances associated with diabetes. Int J Mol Sci 20: 1658, 2019.

26. Vaziri ND: HDL abnormalities in nephrotic syndrome and chronic kidney disease. Nat Rev Nephrol 12: 37-47, 2016.

27. Reiss AB, Voloshyna I, De Leon J, Miyawaki N and Mattana J: Cholesterol metabolism in CKD. Am J Kidney Dis 66: 1071-1082, 2015.

28. Ferro CJ, Mark PB, Kanbay M, Sarafidis P, Heine GH, Rossignol P, Massy ZA, Mallamaci F, Valdivielso JM, Malyszko J, et al: Lipid management in patients with chronic kidney disease. Nat Rev Nephrol 14: 727-749, 2018.

29. Reiser J and Sever S: Podocyte biology and pathogenesis of kidney disease. Annu Rev Med 64: 357-366, 2013.

30. Sieber $\mathbf{J}$ and Jehle AW: Free fatty acids and their metabolism affect function and survival of podocytes. Front Endocrinol (Lausanne) 5: 186, 2014.

31. Zou K, Li Z, Zhang Y, Zhang HY, Li B, Zhu WL, Shi JY, Jia Q and Li YM: Advances in the study of berberine and its derivatives: A focus on anti-inflammatory and anti-tumor effects in the digestive system. Acta Pharmacol Sin 38: 157-167, 2017.

32. Cheng F, Wang Y, Li J, Su C, Wu F, Xia WH, Yang Z, Yu BB, Qiu YX and Tao J: Berberine improves endothelial function by reducing endothelial microparticles-mediated oxidative stress in humans. Int J Cardiol 167: 936-942, 2013.

33. Saha SK and Khuda-Bukhsh AR: Berberine alters epigenetic modifications, disrupts microtubule network, and modulates HPV-18 E6-E7 oncoproteins by targeting p53 in cervical cancer cell HeLa: A mechanistic study including molecular docking. Eur J Pharmacol 744: 132-146, 2014.
34. Zhang Y, Li X, Zou D, Liu W, Yang J, Zhu N, Huo L, Wang M, Hong J, Wu P, et al: Treatment of type 2 diabetes and dyslipidemia with the natural plant alkaloid berberine. J Clin Endocrinol Metab 93: 2559-2565, 2008

35. Wu U, Cha Y, Huang X, Liu J, Chen Z, Wang F, Xu J, Sheng L and Ding H: Protective effects of berberine on high fat-induced kidney damage by increasing serum adiponectin and promoting insulin sensitivity. Int J Clin Exp Pathol 8: 14486-14492, 2015.

36. Sun Y, Yuan X, Zhang F, Han Y, Chang X, Xu X, Li Y and Gao X: Berberine ameliorates fatty acid-induced oxidative stress in human hepatoma cells. Sci Rep 7: 11340, 2017.

37. Qin X, Zhao Y, Gong J, Huang W, Su H, Yuan F, Fang K, Wang D, Li J, Zou X, et al: Berberine protects glomerular podocytes via inhibiting Drp1-mediated mitochondrial fission and dysfunction. Theranostics 9: 1698-1713, 2019.

38. Kaufman RJ: Stress signaling from the lumen of the endoplasmic reticulum: Coordination of gene transcriptional and translational controls. Genes Dev 13: 1211-1233, 1999.

39. Begum G, Harvey L, Dixon CE and Sun D: ER stress and effects of DHA as an ER stress inhibitor. Transl Stroke Res 4: 635-642, 2013.

40. Gardner BM, Pincus D, Gotthardt K, Gallagher CM and Walter P: Endoplasmic reticulum stress sensing in the unfolded protein response. Cold Spring Harb Perspect Biol 5: a013169, 2013.

41. Verfaillie T, Garg AD and Agostinis P: Targeting ER stress induced apoptosis and inflammation in cancer. Cancer Lett 332: 249-264, 2013

42. Chen Y, Wu Z, Zhao S and Xiang R: Chemical chaperones reduce ER stress and adipose tissue inflammation in high fat diet-induced mouse model of obesity. Sci Rep 6: 27486, 2016.

43. Cabral-Miranda F and Hetz C: ER stress and neurodegenerative disease: A cause or effect relationship? Curr Top Microbiol Immunol 414: 131-157, 2018.

44. Ariyasu D, Yoshida H and Hasegawa Y: Endoplasmic reticulum (ER) stress and endocrine disorders. Int J Mol Sci 18: 382, 2017.

45. Cybulsky AV: Endoplasmic reticulum stress, the unfolded protein response and autophagy in kidney diseases. Nat Rev Nephrol 13: 681-696, 2017.

46. Szegezdi E, Fitzgerald U and Samali A: Caspase-12 and ER-stress-mediated apoptosis: The story so far. Ann N Y Acad Sci 1010: 186-194, 2003.

47. Coppolino G, Leonardi G, Andreucci M and Bolignano D: Oxidative stress and kidney function: A brief update. Curr Pharm Des 24: 4794-4799, 2018.

48. Gai Z, Wang T, Visentin M, Kullak-Ublick GA, Fu X and Wang Z: Lipid accumulation and chronic kidney disease. Nutrients 11: 722, 2019.

49. Seervi M, Rani A, Sharma AK and Santhosh Kumar TR: ROS mediated ER stress induces Bax-Bak dependent and independent apoptosis in response to Thioridazine. Biomed Pharmacother 106: 200-209, 2018

50. Malhotra JD and Kaufman RJ: Endoplasmic reticulum stress and oxidative stress: A vicious cycle or a double-edged sword? Antioxid Redox Signal 9: 2277-2293, 2007.

51. Cao SS and Kaufman RJ: Endoplasmic reticulum stress and oxidative stress in cell fate decision and human disease. Antioxid Redox Signal 21: 396-413, 2014.

52. Yu W, Sheng M, Xu R, Yu J, Cui K, Tong J, Shi L, Ren H and Du H: Berberine protects human renal proximal tubular cells from hypoxia/reoxygenation injury via inhibiting endoplasmic reticulum and mitochondrial stress pathways. J Transl Med 11: 24, 2013.

53. Zhu L, Han J, Yuan R, Xue L and Pang W: Berberine ameliorates

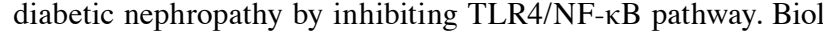
Res 51: 9, 2018

54. Feng X, Sureda A, Jafari S, Memariani Z, Tewari D, Annunziata G, Barrea L, Hassan STS, Smejkal K, Malaník M, et al: Berberine in cardiovascular and metabolic diseases: From mechanisms to therapeutics. Theranostics 9: 1923-1951, 2019.

This work is licensed under a Creative Commons Attribution-NonCommercial-NoDerivatives 4.0 International (CC BY-NC-ND 4.0) License. 